\title{
CP ALL and the Case of Value Web Creation
}

\author{
Bryane Michael, University of Hong Kong and Oxford University \\ Christopher Hartwell, Kozminski Business School \\ Vladimir Korovkin, Skolkovo Institute of Emerging Market Studies
}

How should convenience store operators like Thailand's CP-ALL construct its value chains? What does economic theory teach us about an under-modelled area of management theory (namely value chains)? In this paper, we use a seemingly unrelated economic model analysing Vietnam to tell us something about the conglomerates running convenience stores licenses like CP-ALL. We find that convenience stores may not want to raise capital from Thai banks and the Bangkok stock market when labour productivity exceeds capital's. We also find that inefficiencies inherent in Thai markets may significantly reduce the optimal size of a convenience store operator like CP ALL. These operators may also (counter-intuitively) need to give up a significant share of their profits to "value service providers" when the cost of capital falls. As such, counter to the usual World Bank nostrums, improvements in Bangkok's stock market and banks may actually hurt firms like CPALL.

JEL Codes: D46, G11, L81, P23

Keywords: convenience stores, Thailand, value chains, value web 


\section{CP ALL and the Case of Value Web Creation \\ Bryane Michael, University of Hong Kong and Oxford University \\ Christopher Hartwell, Kozminski Business School \\ Vladimir Korovkin, Skolkovo Institute of Emerging Market Studies}

\section{Introduction}

Better capitalized financial markets help businesses grow. They decrease the need for conglomerates and business groups which can produce and distribute cheap capital among members. Or do they? Such a question holds particular relevance for companies like the Thai 7-Eleven franchise operator CP ALL. CP ALL - a subsidiary of Thailand's largest private company Charoen Pokphand - has seemingly inserted its 7-Elevens in a wider "value web." Such value webs seemingly allow Charoen Pokphand to combine various related economic activities together in a way that Thailand's open markets can not with contracts. Yet, the disparate services providers which make up CP ALL's value chain have bargaining power which may make CP ALL's success a bigger boon for them than for Charoen Pokphand. How to think about the division of spoils between CP ALL and those that provide it with the services which contribute to its value chains? Why does CP ALL seem to avail itself of far less capital from the Bangkok stock market and banks than its foreign peers?

In this paper, we provide a model of the best "location” for firms like CP ALL's service providers along its various value chains. ${ }^{1}$ We also hypothesize that increases in capital and/or decreases in the cost of capital - may actually decrease CP ALL's ability to expand its economic footprint. Similarly, increases in labour's productivity (and wages) as Thailand develops may put companies like CP ALL in peril - as their value service providers sap away their profits. If true, such a model would offer important caveats to the emerging consensus among economists that the increasing wages and labour productivity concomitant with development leads to business development. The model also potentially provides exceptions to the consensus that capital market development helps promote business development.

\section{Literature Review}

Few economists have attempted to seriously modelled value chains - be they in the retail and convenience store segments -- or elsewhere. Until now, most students of economics and business have contented themselves with drawing boxes and arrows around various parts of a business' operations (Walters and Rainbird, 2007). Economists have modelled value-added processes (Koopman et al., 2008). Yet, a mathematically rigourous model which puts the arrows Michael Porter (1985) drew in this book into a framework of Greek letters remains sorely lacking.

\footnotetext{
${ }^{1}$ This paper provides the more formal model inspiring our INSEAD Emerging Markets Institute blog entry about CP ALL. For the lighter analysis, see Bryane Michael, CP All: The Case of the Foreign Licensing Agreement Turned Value Web, available online at: https://blogs.insead.edu/emi/cp-all-the-case-of-the-foreign-licensing-agreement-turned-value-web/
} 
Economists seeking models of convenience store strategy and business organisation generally must make due with a literature focusing on where convenience stores like 7Elevens should locate geographically. Eaton and Tweedle (2012) look at the location decision, using a simple Hotelling model. Sato (2009) looks more at the strategic aspects such a location decision. Looking specifically at Thailand - a study potentially of great relevance for our own analysis of CP ALL - Ngaochay and Walsh (2011) provide a more qualitative than modelling-based analysis. To sum up the current state of economic modelling of value chains, economists have few models from which to derive inspiration.

Yet, a simple reframing of models from other contexts can provide simple, yet powerful, tools for analysing value chains. Models like Eaton and Tweedle - and their brethren look at location in geographical space. Yet, why not reframe "location" not in terms of geographical space, but product space? Convenience stores can choose to provide a host of services from a range of different possible services. Seim's (2006) model provides a flavour of such an approach - looking at the choice of product-types along a potential range or continuum of choices. Yet, rather than extending on Seim-like models, academics have opted for the easier - and non-mathematically rigorous - approach by describing the value chain construction decision in qualitative terms (Brynjolfsson et al., 2009).

Location models can help reframe the value-chain decision. Figure 1 shows how to think about the "location" of a convenience store in service value attribute space rather than geographical space. Marketers have long been familiar with the concept of "value space." Yet, economists have not yet used their tools to formalize companies' value chain construction decision.

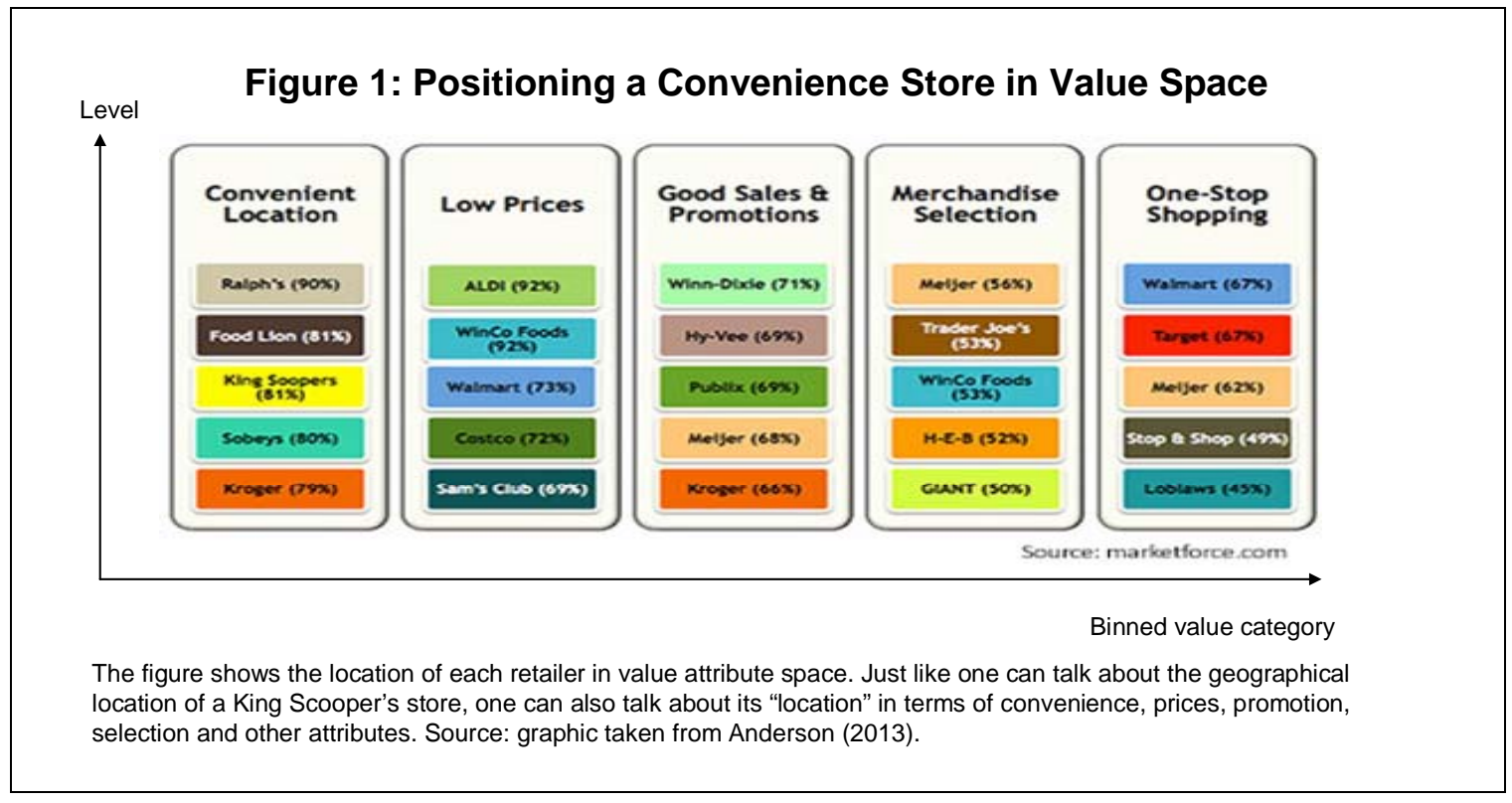

Having a model of convenience stores' value chains' "location" in product/service space (rather than geographical space) allows us to avail ourselves of the range of models which explain how investment and interest rates affect these value chains. If we assume 
that the firm is a black-box collection of value chains (and thus abstract away from explaining them for the time being), a number of authors would suggest that more and cheaper capital leads to business growth (and thus the growth in their value chains). Levine and Zervos (1996) and Love (2003) find a positive correlation between stock market development and economic growth. Yet, they provide no theoretical model which might open up the black box of the firm for potential modellers like us. Alfaro and coauthors (2006) provide an extensive and rigorous model of the way adding capital to a firm can impact on its growth prospects. However, they leave out capital - making their supposed model of the link between financial markets and development unusable for our purposes. Even the most basic economics primer looks at the way changes in the cost of capital affects corporate growth. Yet, surprisingly few models attempt to take the basic models from microeconomics and apply them in a business context like CP ALL's.

Our paper hopes to contribute to the literature in four ways. First, we use one of the simplest "location" models - from a seemingly completed unrelated area of economics to show how even using a simple model can provide deep insights about the way convenience store operators share profits with those sitting on their value chains; and the way changes in investment and returns to investment affect their decisions. Hopefully, we will inspire a generation of business scholars to look to the production of economic models coming out in places like NBER Working Papers to inspire their own model building. Second, we show the counter-intuitive relationship between labour productivity (and wages) and value service providers' ability to extract part of convenience stores' profits. Third, we show that in potentially highly distorted markets like Thailand, optimal convenience store sizes would be miniscule relative to their US or EU counterparts, partly because such inefficiency allows value service providers to extract some of productivity's benefits. Fourth, we show that as companies like CP ALL's cost of capital decreases, they may not increase investment. Such a result sheds further light on the way companies fail to add productive investment even when interest rates fall.

\section{Qualitative Overview of the Model}

Our model revolves around two facets of retailing: extending the value chain (a linear model) to that of a value netlweb (which considers "horizontal" or various dimensions of value) and the need for capital to promote productivity. Retailing generally involves transforming inputs into merchandize bought from a supplier and sold to a universe of buyers. Management theorists usually depict this as a linear process. Value chain profits over time come from retailers' markups and the quantity of goods sold with these mark-ups. The "velocity of sales" might refer to the rate at which retailers can sell these marked-up goods in each time period. Following the law of demand, the higher the mark-up, the lower the quantity demanded.

In a perfectly competitive market, firms will sell goods at the same "velocity" and at the same retail price. As all the retailers have equal access to merchandize suppliers, who sell to all retailers at the same competitive price, - mark-ups will cover these retailers' average operating and other costs. In other words, all retailers will earn no profits.

In the rarefied world of economic theory, retailers can not escape from an equilibrium level of sales which produce no long-term profits. In the real-world, retailers can avail themselves of two strategies. First, retailers can increase their sales over time (their velocity of sales) by offering 
lower prices. Retailers can avail themselves of bargaining power to negotiate bulk-rate discounts, squeeze economies out of their supply chains, or drive down the cost of their machines and workers through production-location decisions and so forth. Cheaper inputs ultimately lead to cheaper outputs (and thus higher levels of demand on classically downward sloping demand curves)..Retailers who contribute to their profit margins by squeeze out these cost-savings will grow their profits with each new sale.

The opposite strategy consists of offering better/different products by pulling together different/better inputs and production processes. Customers might buy commoditized bread, guns and clothes in theory. Yet, they buy differentiated brands in practice. The shopping experience consists of a number of "margins" - like better store locations, more parking space, friendly personnel, spacy and tidy shelves, and so forth. Their customers pay a premium to retailers who manage to differentiate themselves on the dimensions of experience, quality, location, and others.

Retailers can combine these two approaches. Wal-Mart for example focuses on the customer experience while squeezing suppliers. Plotting these two dimensions would result in the retailers value space. The value space consists of the range of different activities the retailer and its suppliers/partners undertake to increase their profits.

Retailer must make the strategic advantages offered by these approaches sustainable and difficult to copy. Creating long-term supplier/partner relationships, purchasing new technologies in logistics, merchandising, marketing, as well as designing proprietary business processes and developing the relevant skills and competences among the employees represent some ways of promoting such sustainability. The retail firm with such sustainable competencies thus positions itself in the middle of its value webs. These value webs consist of suppliers who provide goods for sale and provide technologies enhancing the quality of those sales. Firms which can create these value webs create a source of sustained competitive advantage. Such competitive advantages allow them to generate profits in excess of their rivals.

To generate the value which leads to sustained competitive advantage, these firms must invest capital and labour. To the extent firms can improve the productivity of such labour and capital, they can reduce their costs and increase the value of the value (pardon the pun) offered. As such, productivity increases lie at the heart of the value web.

\section{Introduction to the Model}

In the original Bai et al. (2013) model, the authors wanted to know to what extent producers would move - in geographical space - when confronted with bribery. They set up their model adding bribery costs (which we label $c$ ) in region $i$ as a drag on profits. Equation (1) shows the profits for a firm producing in region $i$. Figure 2 shows what each variable and parameter in the equation means, for readers who did not see this equation ad nauseum during their economics education. We also provide variables we will use later in the paper in the figure, to provide a single place readers can refer to if they need to look up a Greek letter. 


$$
\pi_{i}=\left(1-c_{i}\right) A K^{\alpha} L^{\beta}-w L-r K
$$

\section{Figure 2: Variables and Parameters at A Glance}

\begin{tabular}{|c|c|c|}
\hline Name & Symbol & Meaning \\
\hline $\begin{array}{l}\text { "location"-based } \\
\text { costs of value- } \\
\text { service providers }\end{array}$ & c & $\begin{array}{l}\text { Originally the bribery rate in a locality, this could represent any } \\
\text { cost, friction or drag which pulls actual profits away from an } \\
\text { optimum. We define this as value-service providers' “cut” of } \\
\text { convenience stores' profits. }\end{array}$ \\
\hline technology & A & $\begin{array}{l}\text { Any factor accounting for technological value-added or another } \\
\text { not attributable to labour and capital (ie total factor productivity). }\end{array}$ \\
\hline capital & $\mathrm{K}$ & A measure of the amount of capital CP ALL or its peers employ. \\
\hline $\begin{array}{l}\text { capital's marginal } \\
\text { product }\end{array}$ & $\alpha$ & $\begin{array}{l}\text { The marginal productivity of capital, measures the impact the size } \\
\text { of the firms, industry's or economy's capital stock on } \\
\text { output/profits. }\end{array}$ \\
\hline labour & $\mathrm{L}$ & Amount of labour CP ALL or relevant analogue employs. \\
\hline $\begin{array}{l}\text { labour's marginal } \\
\text { product }\end{array}$ & $\beta$ & How much final value-added workers produce. \\
\hline wage rate & $\mathrm{w}$ & average amount paid to CP ALL's workers. \\
\hline cost of capital & r & $\begin{array}{l}\text { usually the real interest rate, but can also represent the cost of } \\
\text { raising money on the Bangkok stock market or from Thai banks. }\end{array}$ \\
\hline \multicolumn{3}{|l|}{ Variables used later } \\
\hline$\mu$ & & $\begin{array}{l}\text { Size of the firm (loosely speaking and adjusted for capital } \\
\text { productivity) }\end{array}$ \\
\hline$\tau$ & $(\alpha+\beta)$ & multi-factor marginal productivity \\
\hline$\omega$ & $\vartheta w \alpha$ & a wage effect \\
\hline$\lambda$ & $A^{1-\eta} r \beta K^{\alpha+\beta}$ & $\begin{array}{l}\text { basically a technology-productivity adjusted amount of money } \\
\text { spent on capital }\end{array}$ \\
\hline
\end{tabular}

The simplest extension shows how a seeming model of corruption can become a model of value chain construction. Imagine that $i$ represents a place in value space (as we described in Figure 1) rather than physical space. Figure 3 shows the hypothetical profits for a convenience store operator along 5 various attributes, which we label A-E. These attributes can be convenience, friendliness, product quality or any other attribute which creates value. The attributes 1-5 represent differing technologies, ownership structures or methods of delivering these values. For example, the point B5 may represent standardized commodity products delivered by a vertically integrated convenience store management company. The point B1 may represent those same standardized commodity products delivered by disintegrated, mom-and-pop stores. 


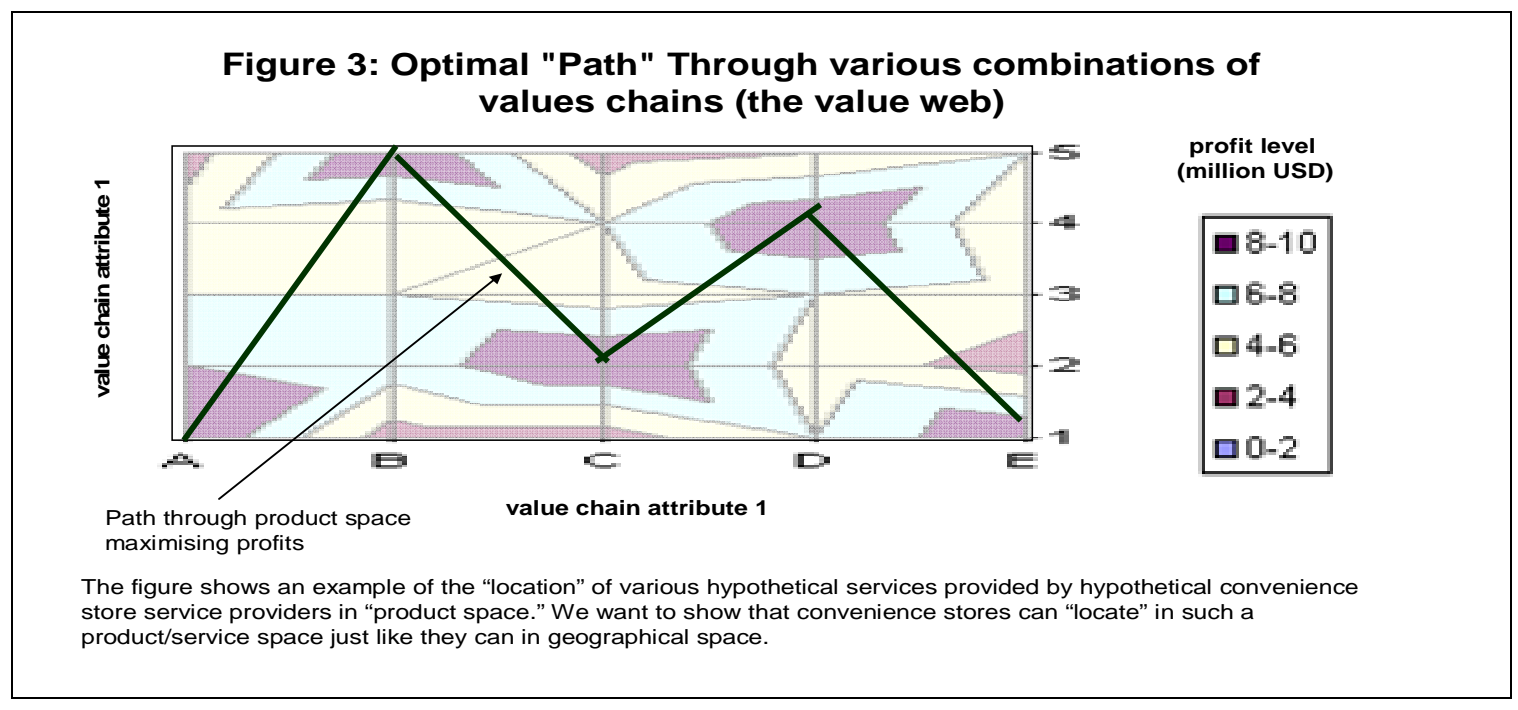

We can simply repeat Bai and coauthor's maths, reinterpreting them to suit our needs. Equation (2) shows that the optimal capital-to-labour ratio used by a convenience store depends on the cost of labour relative to capital $(w / r)$ and the marginal productivity of labour relative to capital $(\alpha / \beta)$. Equation (3) notes that the optimal amount of capital employed depends on its cost $r$ and its productivity $\beta$. As convenience stores choose worse "locations" in value space, as denoted by a higher $c_{\mathrm{i}}$, the amount of capital they must employ rises. The best amount of capital falls as the cost of capital rises (as shown by the term with the $-\beta$ exponent. The optimal amount of capital falls as productivity rises (as shown by the exponent with the $1 /(\alpha+\beta-1)$ term.

$$
\frac{K}{L}=\frac{w \alpha}{r \beta}
$$

$K^{*}=\left(\frac{r}{(1-c) A \alpha}\left(\frac{r \beta}{w \alpha}\right)^{-\beta}\right)^{\frac{1}{\alpha+\beta-1}}$

The authors add "moving costs" in order to derive the best place to move production. Equation (4) shows their simple, elegant and powerful model of location costs $l$. They model them basically as a function of a random shock $\varepsilon$. For our purposes, we can think of these shocks as changes in technologies. Continuing with our example from Figure 3, differences in these costs when moving from 1B to 3D would represent different technologies A, differing costs of moving from one type of service offering to the next $(\theta)$ and the geometric cost of making such changes $(\eta)$, as scraping a large service offering represents a larger cost than simply "moving” a smaller one.

$l=\theta A^{\eta} \varepsilon$

Following the Bai et al. model intuition, differences in adjustment costs (between differing values in what we have called value-space) account for differences in profits. 
Equation (5) shows that the difference in profit from offering one set of value propositions to another depends on "moving costs" (which in our reinterpretation consist of re-gearing, changing suppliers and so forth). ${ }^{2}$ As shown in equation (6), the technological changes (including changes which affect the cost of vertical, horizontal and cross-supply chain integration) would drive differences in convenience stores' profit margins. Whereas 7-Eleven stores may operate independently of a parent corporation in the US (for example), organisational costs and benefits driving $\varepsilon$ in Thailand may encourage integration with a parent like Charoen Pokphand. Nothing about the equations we have provided so far differs from Bai et al... except the interpretation.

$$
\begin{aligned}
& \pi_{1 C} *=\pi_{2 C} *-\theta A^{\eta} \varepsilon \\
& \varepsilon \geq \frac{\pi_{1 C}-\pi_{2 C}}{\theta A^{\eta}}
\end{aligned}
$$

Imagine that - instead of $c$ representation some departure from optimum profits $-c$ represents the rents from some technological differentiation which firms can appropriate. In the convenience store context, imagine that $c$ represents some gain from the Slurpee manufacturers when 7-Elevens use their technology. Suppliers to convenience stores and the stores themselves - want to offer specific services which convenience stores can not do without. These "cost” providers - in fact providers of specific technologies which allow convenience stores to "locate" on a particular part of the value map in the first place - try to maximise $c$ in equation (7). These suppliers want convenience stores to profit from their services. If they set $c$ too low, they give money away to the convenience stores. If they set $c$ too high, they choke off convenience stores' profits.

$$
c_{i} A K^{\alpha} L^{\beta}\left(1-\frac{\pi_{2 C}-\pi_{1 C}}{\theta A^{\eta}}\right)-w L-r K
$$

The capital convenience stores employ depends on the "costs" the value chain service providers charge. In line with the typical intuition behind any kind of optimisation, they maximise their own profits when the change in capital (and other factors) no longer change in response to these changing “costs.” Equation (8) shows Bai and co-authors' best cost $c$. Equation (9) shows the way that such costs depend on factors like the productivity of capital. We use equation (9) as a point of departure from Bai et al.'s model.

$$
K^{*}+c_{1}(\alpha+\beta) \frac{d K^{*}}{d c_{1}}+\frac{c_{1} K^{*}}{\theta A^{\eta}} \frac{d \pi_{1}}{d c_{1}}=0
$$

\footnotetext{
${ }^{2}$ We are relatively relaxed about our mathematical formality at this point (particularly in terms of providing subscripts) as we don't want to stray too far away from Bai et al.'s original conception. Naturally, the variables comprising the moving costs we show in equation (5) would consist of matrices whose final product would equal the same rank as the "value space” we depict in Figure 2.
} 


$$
\left(\frac{1}{\vartheta} A^{1-\eta}\left(\frac{r \beta}{w \alpha}\right)^{\beta} K^{\alpha+\beta}+\frac{\alpha+\beta}{1-\alpha-\beta} \frac{1}{1-c}\right) c=1
$$

The Division of Proceeds between Convenience Stores and Service Providers

\section{Basic model intuition}

What do we know about the value-service providers maximising their returns? Recall from equation (1) that (1-c) of convenience stores' profits pass on to them. As we described in equation (7) value chain service providers seek to maximise $c$. The core insight of the model consists of the tug-of-war between convenience stores which try to maximise (1-c) and their value chain providers who want to maximise the value of c. Figure 4 describes how the variables and parameters in equation (9) help determine that trade-off between $c$ and $(1-c)$. Just eye-balling the equation, we see that labour productivity $(\alpha)$, capital's productivity $(\beta)$ and the relative cost of capital $(r / w)$ affect this trade off in ways we will describe in this paper.

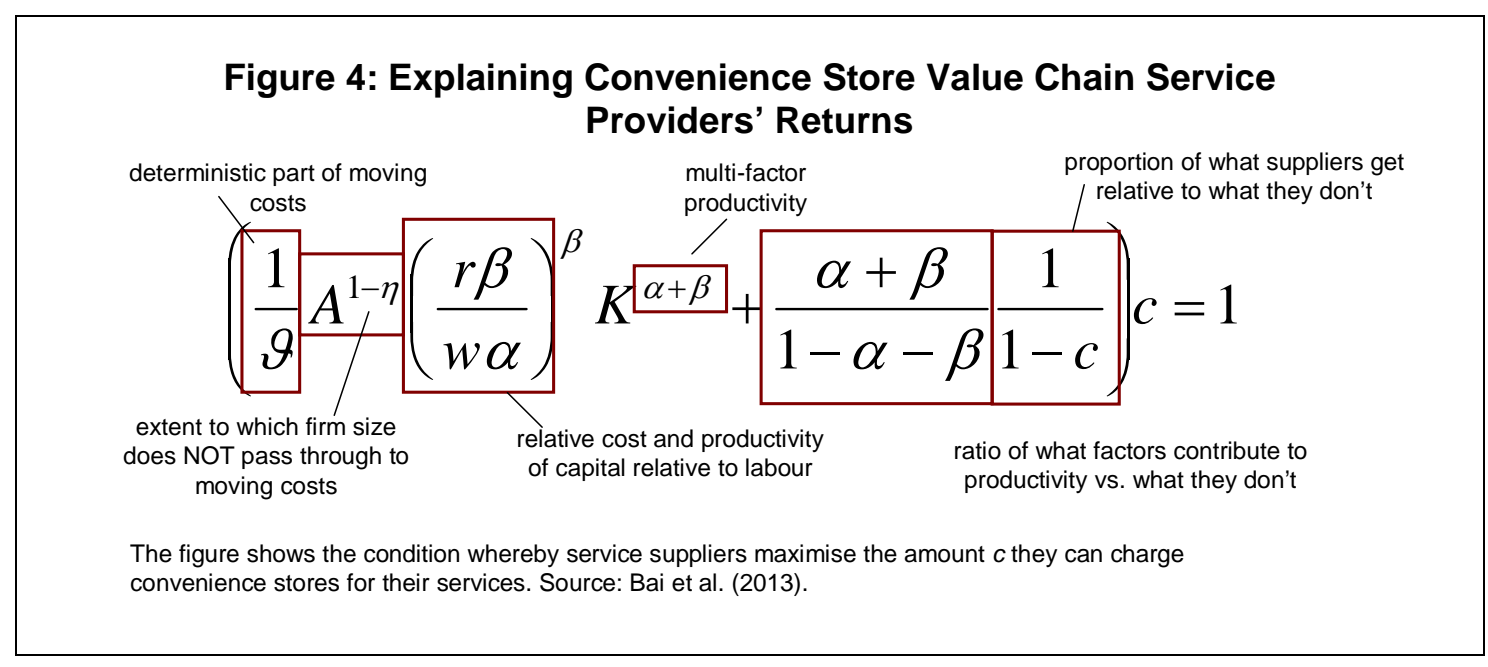

What determines the way convenience stores and services providers share profits?

Lemma 1: The cooperative part of value providers and convenience stores equals $(\alpha+\beta) r \beta^{\beta} A^{1-\eta} K^{\alpha+\beta}$, and the competitive part equals $(1-\alpha-\beta) \vartheta(w \alpha)^{\beta}$.

In order for both value-service providers and convenience stores to benefit, (1-c) must rise at the same time that c rises. Equation (9a) reorganises equation (9) to show how (1-c) varies with $c$. Everything that rises in the numerator increases the value of $(1-c)-$ namely $(\alpha+\beta) r \beta^{\beta} A^{1-\eta} K^{\alpha+\beta}$. Naturally, increasing productivity to labour and capital benefit both value providers and convenience store owners by "expanding the economic pie." Increasing scale and scale effects also go to convenience store operators (as value providers do not observe all the benefits). Increases in capital deployed also increase convenience stores' share of the gains. Such results do not differ substantially from 
Giannoccaro and Pontrandolfo (2004), who also note that - in a supply-chain setting various parts of the chain can benefit all together.

$$
\frac{(1-c)}{c}=\left(A^{1-\eta} K^{\alpha+\beta} \frac{r \beta^{\beta}}{\vartheta(w \alpha)^{\beta}} \frac{\alpha+\beta}{1-\alpha-\beta}\right)
$$

What about the factors that increases bargaining frictions between convenience stores and value service providers? Clearly, any factor productivity not attributable to labour or capital (namely $1-\alpha-\beta$ ) as well as the observable part of convenience store scale $(\theta)$ would increases these tensions. Convenience store owners can hardly directly claim that their results lead to profitability - thus these seeming extra gains represent the first targets in any negotiation. Interestingly, labour productivity - and the higher wages such productivity attracts - tends to increase value service providers' share of the economic pie. Already, such an observation provides for deep insights when game theoretic and other treatments like Yao et al. (2008) do not provide. Such an observation leads us to prediction 1.

Prediction 1: Value service providers' net income will rise relative to convenience stores' net income when wage growth undue to productivity growth outstrips interest rate growth.

Equation (9b) can help illustrate this prediction. In that equation, we show the proportional returns to convenience stores as a percent of returns to value service providers. In theory, rising wages would reflect increasing labour's marginal productivity $\alpha$ relative to capital's $\beta$. As an a appears in both the numerator and denominator, the term $(1-\alpha-\beta) /(\alpha+\beta)$ would become smaller. On the other hand, the term, $w^{\beta} / r$ would become larger.

$$
\frac{c}{(1-c)}=\left(\frac{1}{A^{1-\eta} K^{\alpha+\beta}} \frac{\vartheta(w \alpha)^{\beta}}{r \beta^{\beta}} \frac{1-\alpha-\beta}{\alpha+\beta}\right)
$$

The economic intuition might be that value service providers, seeing labour militating for higher "unjustified" returns would do similarly. Such a reaction could only occur when convenience stores have some degree of market power driving up profits about the level needed to pay factors of production - otherwise no resources would remain to satisfy the demands of value added providers. In a more competitive situation, labour and service providers would need to split the benefits that higher labour productivity provides.

\section{Equilibrium returns to value service providers}

How much money can value service providers earn? Equation (9b) provides the intuition for the relative distribution of "spoils" between convenience stores and their value service providers. Recall that $c$ in fact can represent a range (vector) of $c_{i}$ of various service providers. Thus, knowing the returns these value service providers can earn can help 
"size" the convenience store industry's related sub-sectors. By implication, their size also determines the optimal size of Thailand's convenience store sector - and thus CP ALL's.

Lemma 2: Convenience store operators can keep all of their profits (and value service providers get nothing) only for special types of production functions, when $\tau=1$ and $\tau=\frac{1-\omega+2 \lambda}{6 \lambda}$ and $\sigma=\frac{1-\tau}{4\left(\alpha^{2}+\beta^{2}\right)}$

and under the Pyrrhic victory case when $r=0, \theta=0, w=0, \alpha=0, \beta=0$, and if the convenience store size equals zero.

So what is c? In other words, how much should these suppliers charge? Equation (10) shows equation (9) which we solved for $c$. Let $\lambda=A^{1-\eta} r \beta K^{\alpha+\beta}$ and let lambda represent the extent to which returns to capital do not pass through. Let $\varpi=\vartheta_{w} \alpha$ and let omega represent a wage effect. Finally, let $\mu=A^{1-\eta} \beta K^{\alpha+\beta}$, where mu equals the effect of capital. The basic intuition of the equation shows that the absolute value of these returns

$$
c=\frac{1}{2 \lambda(-1+\tau)} \sqrt{\lambda^{2}\left(1-2 \tau+\tau^{2}\right)-\lambda\left(1-\tau-4 \omega\left(\alpha^{2}+\beta^{2}\right)\right)-\omega(\omega-2 \lambda+6 \lambda \tau-1)}
$$

When do value service providers receive none of the economic pie. In that case $c=0$, and equation (11) shows the condition under which that is true. If $q=\left(1-\tau-4 \omega\left(\alpha^{2}+\beta^{2}\right)\right)$, $\mathrm{z}=2\left(1-2 \tau+\tau^{2}\right)$, then equation (12) shows the case more clearly. Equation (11) is true when the denominator in under the radical equals zero, namely when $\tau=1$. Alternatively, when the last term equals zero, namely when ${ }_{\tau=\frac{1-\omega+2 \lambda}{6 \lambda}}$ and $\sigma=\frac{1-\tau}{4\left(\alpha^{2}+\beta^{2}\right)}$

$0=\frac{1}{2 \lambda(-1+\tau)} \sqrt{\frac{\left(1-\tau-4 \omega\left(\alpha^{2}+\beta^{2}\right)\right) \pm \sqrt{\left(1-\tau-4 \omega\left(\alpha^{2}+\beta^{2}\right)\right)^{2}-4 \omega\left(1-2 \tau+\tau^{2}\right)(\omega-2 \lambda+6 \lambda \tau-1)}}{2\left(1-2 \tau+\tau^{2}\right)}}$

$0=\frac{1}{2 \lambda(-1+\tau)} \sqrt{\frac{q \pm \sqrt{q^{2}-2 \omega z(\omega-2 \lambda+6 \lambda \tau-1)}}{z}}$

One other situation exists where value service providers get nothing. And what about when they get nothing (in other words convenience stores get all the benefits)? For equation (9b bis) to equal zero, any one of the factors or variables can equal zero. If $r=0$, $\theta=0, w=0, \alpha=0, \beta=0$, and if the convenience store size equals zero, then convenience stores obtain the Pyrrhic victory of getting $100 \%$ of $\$ 0$.

Corollary 1: Value service providers obtain all the benefits of convenience stores' efforts only under the very particular case when convenience store sizes correspond to $(1-\alpha-\beta) /(\alpha+\beta) *\left(\vartheta(w \alpha)^{\beta} / r \beta^{\beta}\right)$, namely when labour "value" (wages and productivity) are extremely high. 
We prove this by returning to equation (9b). After setting $c /(c-1)=1$, and some math, equation (13) shows that these value service providers obtain all the benefits when the scale of convenience stores $\left(\mathrm{A}^{1-\eta} \mathrm{K}^{\alpha+\beta}\right)$ equals just the right proportion of wages (and labour productivity) to capital returns and capital productivity. Remember that usually $\alpha<1$ and $\beta<1$ and $\mathrm{A}$ as well as $\mathrm{K}$ must represent large figures (in the millions of dollars).

$$
A^{1-\eta} K^{\alpha+\beta}=\frac{\vartheta(w \alpha)^{\beta}}{r \beta^{\beta}} \frac{1-\alpha-\beta}{\alpha+\beta}
$$

If we set $\alpha=.6$ and $\beta=.2$, just for the sake of a concrete example, then equation (14) shows exactly how big that convenience store size should be. Notice that such a relation depends on the wage rate relative to the real interest rate (market returns to capital). All other things being equal - and assuming that the value of convenience stores comes in at a standardized value of 1 , equation (15) shows that such wages must equal roughly half of such a standardized value (before taking interest rates and $\theta$ into account).

$$
\begin{aligned}
& A^{1-\eta} K^{\alpha+\beta}=\frac{5 \theta}{4} \sqrt[5]{\frac{.6 w}{r}} \\
& w=1.66\left(\frac{4}{5 \theta}\right)^{5} r, w=.544 \frac{r}{\theta}
\end{aligned}
$$

\section{Thinking through the case of Thailand}

How would competition for profits change in a perfectly competitive system?

We saw previously that the division of profits between convenience stores and their value-service providers depends on labour and capital productivity. Rattso and Stokke (2003) represent one of the many voices provides evidence about the gap between Thai productivity levels and those in the US and EU. As such, it makes sense to consider how the division of spoils differs when technology size (basically firm size) and productivity shocks affect equation (9).

Lemma 3: Differences in productivity translate into lower value service providers' shares of profits if $\tau>1$ or $\lambda / \omega<1$.

When do convenience stores increase their share of profits relative to value service providers? Equation (16) shows the way $c /(1-c)$ changes with a change in technological factor $A$. All the terms in equation (16) are positive. Thus, any decrease in $c /(1-c)$ must correspond with either an impossible negative value for $(1-\eta)$ or increasing returns to scale (such that $\tau>1$ ). When $\tau>1,(1-\tau)>0$ and the whole expression becomes negative. Similarly for equation (17) and equation (18), $c /(1-c)$ decreases when either $\lambda / \omega<1$ or again when $\tau>1$. In other words, differences in alpha and beta only make a difference for very small, wage intensive firms. 


$$
\begin{aligned}
& \frac{d(c /(1-c)}{d A}=\frac{K^{\tau}}{\theta A^{-\eta}} \frac{r}{w} \frac{(1-\eta)(1-\tau)}{\alpha \tau}=0 \\
& \frac{d(c /(1-c)}{d \alpha}=\frac{\left(\frac{\lambda \ln (K)}{\varpi}-\frac{\lambda}{\alpha \varpi}\right)(1-\tau)}{\tau}-\frac{\left(\frac{\lambda}{\varpi}-1\right)}{\tau}-\frac{\left(\frac{\lambda}{\varpi}-1\right)(1-\tau)}{\tau^{2}} \\
& \frac{d(c /(1-c)}{d \beta}=\frac{\left(\frac{A^{1-\eta} r K^{\tau}}{\varpi}+\frac{\lambda \ln (K)}{\alpha \varpi}\right)(1-\tau)}{\tau}-\frac{\left(\frac{\lambda}{\varpi}-1\right)}{\tau}-\frac{\left(\frac{\lambda}{\varpi}-1\right)(1-\tau)}{\tau^{2}}
\end{aligned}
$$

Prediction 2: Convenience stores exhibiting strongly decreasing returns to scale should have a large value webs (large numbers of different value chain service providers) and increasing returns to scale should have smaller value webs.

If we can believe anecdotal evidence, the model's prediction seems well confirmed. Local newspapers have already said "bye bye big stores, hello small stores." 3 The model also explains why some countries have experienced the "supermarket revolution" - while others haven’t (Reardon and Hopkins, 2006).

\section{Does more bank and stock market capital make CP ALL better off?}

How does the optimal amount of capital change as service providers' power strengthens?

How does the optimal amount of capital deployed by convenience stores change in response to various factors? Equation (19) shows the extent to which convenience stores deploy capital. Their capital allocation decision clearly depends on c, $\tau$ (multifactor productivity) and $\omega$ (a factor encapsulating labour/wage effects). As multi-factor productivity rises, so does the optimal amount of capital deployed. As expected, as value providers take a larger share of the pie, the optimal level of capital falls.

$$
K=\left(\frac{\left(\frac{1}{c}-\frac{\tau}{(1-\tau)(1-c)}\right) \omega}{A^{1-\eta} r \beta}\right)^{\frac{1}{\tau}}
$$

Changes in the cost of capital - whether such capital comes from banks or the stock market - determines the amount of capital convenience stores deploy. Equation (20) shows how this amount of optimal capital changes as the cost of capital changes. The changes match our intuitions. Increases in convenience store sizes (shown by $\mathrm{A}^{1-\eta}$ ) also tend to reduce capital's response to a changing cost of capital. Interestingly, the way capital changes in response to changes in the cost of capital does not depend on the level of the firm's previous investment (namely its level of capital). As value service providers

\footnotetext{
${ }^{3}$ Pitsinee Jitpleecheep, Bye bye big stores, hello small stores, 2013, available online.
} 
increase their share of convenience stores' profits, the sensitivity of capital with respect to the cost of capital falls.

$$
\frac{d K}{d r}=\frac{1}{\tau * r} \frac{\left(\left(\frac{1}{c}-\frac{\tau}{(1-\tau)(1-c)}\right) \varpi\right)^{\frac{1}{\tau}}}{\left(A^{1-\eta} \beta\right)}
$$

Prediction 3: To the extent Thailand productivity falls short of productivity in other countries, companies like CP ALL's optimal capitalization remain less sensitive to the cost of capital than in other places.

Equation (20) shows the basis for our third prediction. Higher levels of capital and labour productivity $\tau$ tend to decrease the amount total investment $(\mathrm{K})$ needs to change when the cost of capital changes - as $\tau$ appears in the radical and in the denominator of the first term of equation (20).

Similarly, the way investment levels in convenience stores changes in response to value service providers share of their profits behaves relatively similarly. Equation (21) shows (unsurprisingly) that as their cut of convenience stores profits rises, the optimal level of capital falls. As factor productivity rises, capital needs to change less in response to increased demands from these value service providers. As such, improving productivity represents an important and useful method of adapting when external factors would require convenience stores to change their "location" in their value chains/webs.

$$
\frac{d K}{d c}=\frac{\left(\frac{\left(\frac{1}{c}-\frac{\tau}{(1-\tau)(1-c)}\right) \varpi}{A^{1-\eta} r \beta}\right)^{\frac{1}{\tau}}\left(-\frac{1}{c^{2}}-\frac{\tau}{(1-\tau)(1-c)^{2}}\right)}{\tau \frac{1}{c}-\frac{\tau}{(1-\tau)(1-c)}}
$$

How would differences in the cost of capital and the amount of money value service providers take affect investment in companies like CP ALL? In other words, what forces would a convenience store's investment experience as $r$ and $c$ change - at different levels of these variables? Equation (22) shows the way convenience stores' total investment changes for changes in the cost of capital and $c$. Economists will recognise the equation as a gradient. In order to provide intuitions into the behaviour of the gradient, we can illustrate with some sample values of several of the variables.

$$
\nabla K=\frac{1}{\tau * r} \frac{\left(\left(\frac{1}{c}-\frac{\tau}{(1-\tau)(1-c)}\right) \sigma\right)^{\frac{1}{\tau}}}{\left(A^{1-\eta} \beta\right)} \hat{r}+\frac{\left(\frac{\left(\frac{1}{c}-\frac{\tau}{(1-\tau)(1-c)}\right) \varpi}{A^{1-\eta} r \beta}\right)^{\frac{1}{\tau}}\left(-\frac{1}{c^{2}}-\frac{\tau}{(1-\tau)(1-c)^{2}}\right)}{\tau \frac{1}{c}-\frac{\tau}{(1-\tau)(1-c)}} \hat{c}
$$


Relatively common sense parameterization of our models shows the forces acting on any convenience store's optimal investment stock. If we set constant returns so $\tau=1$, and $A^{\wedge 1-}$ $\eta=1$, Figure 5 shows TWO stable paths through the cost of capital and the proportion of returns gained by value service providers. If the initial cost of capital is too low, then the amount of money demanded by value service providers skyrockets quickly - and the whole enterprise collapses on itself. If the cost of cost of capital is high enough, then convenience stores

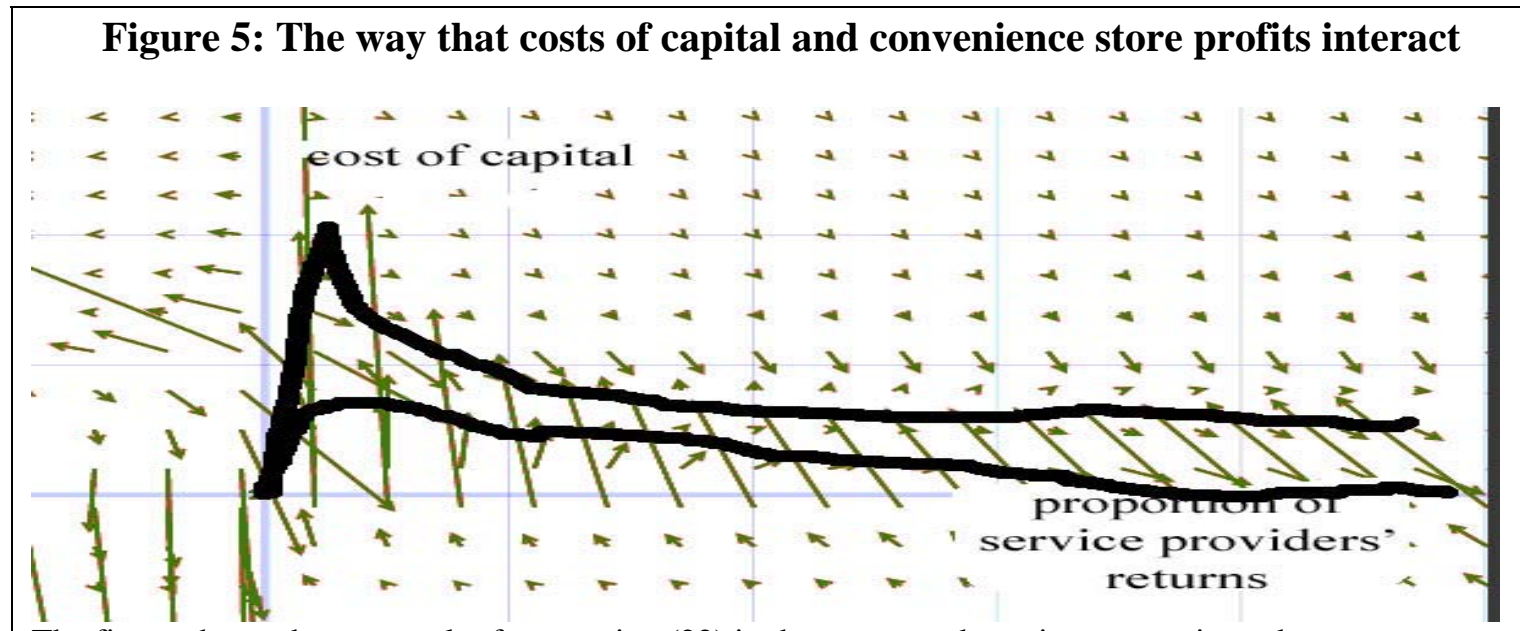

The figure shows the vector plot for equation (22) in the paper, under strict assumptions about constant returns to scale and a unit value of technology and capital.

Prediction 4: For reasonable parameterizations, the cost of capital for any convenience store group like CP ALL must exceed 66\% per annum in order to give convenience stores enough bargaining power to keep most of their profits. Once solidified in their gains, they will have high costs of capital and low levels of sharing with these service providers.

Our prediction comes from eye-balling figure 5. Assuming we have plotted the equation correctly, we have tried to draw the two steady-state paths in the figure in black. As shown, the proportion of service providers' returns $(c /(1-c))$ seems to increase no matter which path the convenience store's investment falls. Yet, that cost of capital can be higher or lower. Moreover, at about $(c /(1-c))=0.5$, dynamic forces seem to act to pull back these benefits with attendant higher costs of capital. This suggests that if convenience store managers manage to negotiate relatively little profit sharing with these value chain "partners" when they first open, they will not need to share in the future. Otherwise, convenience stores seem to trade-off payments to capital providers for payments to value-chain partners.

Prediction 5: Convenience stores will have no profits after accounting for dissipation in the cost of capital and value service providers' payments.

Firms do not make abnormal profits, otherwise they either get competed away or spend on factors of production and inputs. Yet, Equation (1) allows for the possibility of such 
profits. Indeed, CP ALL indeed continues to make profits. ${ }^{4}$ How much profit (1-c) should convenience stores like CP ALL make over time? Let's assume for the moment that profits represent an undetermined function of profits $\pi(K)$. We will show shortly why we leave the functional form general rather than solve one of our previous equations to derive the exact relationship. Equation (23) shows then the stock of potential profits for various levels of capital as we integrate over various costs of capital and levels of value service provider payments (which we normalize between 0 and 1). Trying to solve for any value doesn't matter -- the result always equals zero. The way capital contributes to profits in our model does not really matter. The model, when we put in values in the range between $0-1$ for $r$ and $c$ comes up zero.

$$
\pi=\pi(K) \int_{0}^{1} \int_{0}^{1}\left[\begin{array}{l}
\frac{1}{\tau * r} \frac{\left(\left(\frac{1}{c}-\frac{\tau}{(1-\tau)(1-c)}\right) \varpi\right)^{\frac{1}{\tau}}}{\left(A^{1-\eta} \beta\right)}+\left(\frac{\left(\frac{1}{c}-\frac{\tau}{(1-\tau)(1-c)}\right)}{A^{1-\eta} r \beta}\right)^{\frac{1}{\tau}} \\
\frac{\left(-\frac{1}{c^{2}}-\frac{\tau}{\tau \frac{1}{(1-\tau)(1-c)^{2}}}\right)}{\tau \frac{\tau}{(1-\tau)(1-c)}}
\end{array}\right] d r d c
$$

The term $(1-\tau)(1-c)$ explains the dissipation of these profits. We noted above that - when convenience stores deploy their optimal capital - they trade-off payments to financiers versus value-chain service providers. No matter how capital finds its way into profits (namely the functional form of $\pi(K)$ ), these profits will dissipate over time. The press articles on CP ALL we have cited in this paper note the company's profits. Yet, mention always appears about the money the company must spend on expansion - namely on $r$ and $c$.

But what about the behaviour of profits in a small localized area? Maybe the "collapse" of equation (23) occurs because we have chosen endpoints corresponding to 0 and 1. How does the cost of capital and these value-chain providers' payments act within this boundary? In other words, does $r$ and c diverge from each other in a small localized area within $0<c<1$ and $0<r<1$ ? Equation (24) provides the answer. To make the maths only slightly more tractable, we set $\rho=\frac{\left(\frac{1}{c}-\frac{\tau}{(1-\tau)(1-c)}\right) \varpi}{A^{1-n} r \beta}$ and $\psi=\frac{1}{c^{2}}-\frac{\tau}{(1-\tau)(1-c)^{2}}$.

\footnotetext{
${ }^{4}$ See Anuchit Nguyen, CP All Plans 10,000 7-Elevens to Sustain Growth: Southeast Asia, Bloomberg, 9 Aug 2012, available at: http://www.bloomberg.com/news/2012-08-09/cp-all-plans-10-000-7-elevens-tosustain-growth-southeast-asia.html
} 


$$
\begin{aligned}
& \nabla \nabla K=\left[\frac{-\rho^{\frac{1}{\tau}} \psi^{2}}{\tau^{2}\left(\frac{1}{c}-\frac{\tau}{(1-\tau)(1-c)}\right)^{2}}+\frac{2 \rho^{\frac{1}{\tau}} \psi^{2}\left(\frac{1}{c^{3}}-\frac{\tau}{(1-\tau)(1-c)^{3}}\right)}{\tau^{2}\left(\frac{1}{c}-\frac{\tau}{(1-\tau)(1-c)}\right)}+\frac{\rho^{\frac{1}{\tau}} \psi^{2}}{\tau^{2}\left(\frac{1}{c}-\frac{\tau}{(1-\tau)(1-c)}\right)^{2}}\right]+ \\
& {\left[\frac{\rho^{1 / \tau}}{\tau * r} \frac{\ln (\rho)}{\tau^{2}}+\left(\frac{\left(\rho /((1-\tau)(1-c))-(\tau / 1-\tau)^{2}(1-c)\right) \varpi}{r}+\tau\right)+\right.} \\
& {\left[\frac{\tau \rho^{2 / \tau}\left(\frac{1}{\tau^{2}}-\frac{1}{c}-\frac{1}{(1-\tau)(1-c)}-\frac{\tau}{(1-\tau)^{2}(1-c)}\right) \varpi}{r^{2}}+\frac{\rho}{r c}-\frac{\tau \theta w}{(1-\tau)(1-c)}\right]}
\end{aligned}
$$

As before the divergence of $r$ and $c$ from each other collapses to zero. After testing the equation for a range of values, all our answers came back undefined. On the one hand, it is extremely vexing to build and use a multivariate calculus study, only to find out the result equals zero. On the other hand, it is gratifying to hypothesize a well-proven result from economics - that firms' profits dissipate into zero. If CP ALL earns large profits now, our model predicts that more of that profit goes to financiers and value-chain partners than meets the eye. To determine the real extent to which these parties share in CP ALL's fortunes, we would need to look at its shareholders, bankers and partners who share in its current bonanza.

\section{Conclusion}

What would a convenience stores "value web" look like in theory? Economics have provided few models to inspire business theorists. Business theorists looking for models of convenience store operators like the Thai CP ALL have even less to grab on to. In this paper, we have taken a simple model from a recent NBER Working Paper series, and adapted it as a potential model of convenience store value chains. We find that convenience stores may not want to raise capital from Thai banks and the Bangkok stock market when labour productivity exceeds capital's. We also find that inefficiencies inherent in Thai markets may significantly reduce the optimal size of a convenience store operator like CP ALL. These operators may also (counter-intuitively) need to give up a significant share of their profits to "value service providers" when the cost of capital falls.

Our model's predictions suggest several things about broader received wisdom of management and economics. First, even developing countries like Thailand's capital markets may not make their convenience store operators more profitable. They profits depend on their value webs/chains - and indeed should come to zero in the longer-term. Second, several possible configurations of value chains/webs exist - with their attendant division of profits with financiers. Contrary to received wisdom in the business literature, no one perfect method may exist (or need to exist) of putting a firm's value chains together. ${ }^{5}$ Third, labour intensive economies - and economies with low multi-factor productivity - may have difficulty developing large, integrated convenience store operators. Economists as far back as Heckscher-Ohlin have theorised about the difficulty of raising the capital intensivities of companies in countries where labour represents the country's comparative advantage. Such an issue plagues Thailand to this day.

\footnotetext{
${ }^{5}$ See Taylor (2005) for a related discussion in the agro-industry.
} 


\section{Bibliography}

Alfaro, Laura, Areendam Chanda, Sebnem Kalemli-Ozcan and Selin Sayek. (2006). How Does Foreign Direct Investment Promote Economic Growth? Exploring the Effects of Financial Markets on Linkages. NBER Working Papers 12522.

Anderson, George. (2013). Why Are Trader Joe's Customers the Most Satisfied in America?

July 25, 2013

http://www.retailwire.com/discussion/16917/why-are-trader-joes-customers-the-mostsatisfied-in-america

Bai, Jie Seema Jayachandran, Edmund Malesky, and Benjamin Olken. (2013). Does Economic Growth Reduce Corruption? Theory and Evidence from Vietnam. NBER Working Paper No. 19483.

Brynjolfsson, Erik, Yu Hu and Mohammad Rahman. (2009). Battle of the Retail Channels: How Product Selection and Geography Drive Cross-Channel Competition. Management Science 55(11).

Eaton, Curtis and Jesse Tweedle. (2012). A Hotelling style model of spatial competition for a convenience good. The Annals of Regional Science 49(2): 447-469.

Giannoccaro, Ilaria and Pierpaolo Pontrandolfo. (2004). Supply chain coordination by revenue sharing contracts. International Journal of Production Economics 89(2): 131-139.

Koopman, Robert, Zhi Wang, and Shang-Jin Wei. (2008). How Much of Chinese Exports is Really Made In China? Assessing Domestic Value-Added When Processing Trade is Pervasive. NBER Working Paper No. 14109.

Levine, Ross and Sara Zervos. (1996). Stock Market Development and Long-Run Growth. World Bank Economic Review 10(2): 323-339.

Love, Inessa. (2003). Financial Development and Financing Constraints: International Evidence from the Structural Investment Model. Review of Financial Studies 16(3): 765791.

Ngaochay, Thanee and John Walsh. (2011). Paths to Success for 7-Eleven in Thailand. Information Management and Business Review 3(1): 1-7.

Porter, Michael. (1985). Competitive Advantage: Creating and Sustaining Superior Performance. 
Rattso, Jorn and Hildegunn Stokke. (2003). Learning and Foreign Technology Spillover in Thailand: Empirical Evidence on Productivity Dynamics. Nordic Journal of Political Economy 29.

Reardon, Thomas and Rose Hopkins. (2006). The Supermarket Revolution in Developing Countries: Policies to Address Emerging Tensions Among Supermarkets, Suppliers and Traditional Retailers. The European Journal of Development Research 18(4).

Sato, Yukihito. (2009). Strategic Choices of Convenience Store Chains in China. 7Eleven and FamilyMart. China Information 23(1): 45-69.

Seim, Katja. (2006). An empirical model of firm entry with endogenous product-type choices. RAND Journal of Economics 37(3): 619-640.

Stephen Roper, Jun Du and James Love. (2011). Modelling the Innovation Value Chain http://eprints.aston.ac.uk/6961/1/Modelling_the_innovation_value_chain.pdf

Sturgeon, Timothy, Johannes Van Biesebroeck and Gary Gereffi. (2008). Value chains, networks and clusters: reframing the global automotive industry. Journal of Economic Geography 8 (3): 297-321.

Taylor, David. (2005). Value chain analysis: an approach to supply chain improvement in agri-food chains. International Journal of Physical Distribution \& Logistics Management, 35(10): $744-761$.

Walters, David and Mark Rainbird, (2007) "Cooperative innovation: a value chain approach. Journal of Enterprise Information Management 20(5): 595 - 607.

Yao, Z., Stephen Leung and K. Lai. (2008). Manufacturer's revenue-sharing contract and retail competition. European Journal of Operational Research 186(2): 637-651. 